\title{
Street triage services in England: service models, national provision and the opinions of police
}

\author{
Abirami Kirubarajan, ${ }^{1}$ Stephen Puntis, ${ }^{2}$ Devon Perfect, ${ }^{3}$ Marc Tarbit, ${ }^{4}$ Mary Buckman, ${ }^{3}$ \\ Andrew Molodynski ${ }^{3}$
}

BJPsych Bulletin (2018) 42, 253-257, doi:10.1192/bjb.2018.62

\author{
${ }^{1}$ Faculty of Medicine, University of \\ Toronto, Canada; ${ }^{2}$ Department of \\ Psychiatry, University of Oxford, UK; \\ ${ }^{3}$ Oxford Health NHS Foundation Trust, \\ Warneford Hospital, UK; ${ }^{4}$ Thames \\ Valley Police, UK \\ Correspondence to Stephen Puntis \\ (stephen.puntis@psych.ox.ac.uk) \\ First received 14 Feb 2018, final revision \\ 6 Jun 2018, accepted 13 Jul 2018 \\ (C) The Authors 2018. This is an Open \\ Access article, distributed under the \\ terms of the Creative Commons \\ Attribution-NonCommercial- \\ NoDerivatives licence (http:// \\ creativecommons.org/licenses/by-nc- \\ nd/4.0/), which permits non- \\ commercial re-use, distribution, and \\ reproduction in any medium, provided \\ the original work is unaltered and is \\ properly cited. The written permission of \\ Cambridge University Press must be \\ obtained for commercial re-use or in \\ order to create a derivative work.
}

\begin{abstract}
Aims and method Street triage services are increasingly common and part of standard responses to mental health crises in the community, but little is understood about them. We conducted a national survey of mental health trusts to gather detailed information regarding street triage services alongside a survey of Thames Valley police officers to ascertain their views and experiences.

Results Triage services are available in most areas of the country and are growing in scope. There is wide variation in levels of funding and modes of operation, including hours covered. Police officers from our survey overwhelmingly support such services and would like to see them expanded.

Clinical implications Mental health crises now form a core part of policing and there are compelling reasons for the support of specialist services. Recent changes to the law have heightened this need, with a requirement for specialist input before a Section 136 is enacted. Those who have experienced triage services report it as less stigmatising and traumatic than a traditional approach, but there remains little evidence on which to base decisions.
\end{abstract}

\section{Declaration of interest None.}

Keywords Police street triage; social psychiatry; crisis intervention.
Law enforcement officers routinely come into contact with members of the public who have mental health problems. In the UK, estimates of police incidents linked to mental health crises have increased over recent years. ${ }^{1}$ Within England and Wales, Section 136 of the Mental Health Act 2007 allows police officers to detain people who are experiencing a mental health crisis and who are considered to pose a risk to themselves or others. ${ }^{2}$ Although this measure may be unavoidable, it is often distressing, expensive and labourintensive. $^{3}$ In addition, police officers often feel that they lack the training to appropriately support those in mental health crisis. ${ }^{4}$

In response to the increasing use of Section 136, the Department of Health funded several regional pilots of street triage for mental healthcare in $2013 .^{5}$ Triage models typically involve mental health professionals working in partnership with police officers, providing expertise through a telephone service or an in-person mobile unit.

More services have now been commissioned at a local and regional level by mental health trusts and police forces. The provision of triage services nationally, however, remains unknown and there is a lack of information regarding the operational models used. There is also no systematic information regarding police officer opinions of such services.
Recent changes to the Policing and Crime Act 2017 made it a legal requirement to consult, where practical, with a mental health professional before instigating a Section $136 .{ }^{6}$ Street triage schemes, whose primary function is to introduce mental health expertise during police incidents, may be ideally placed to do this. As mental health police partnerships become more vital at the point of crisis, information on service models will enable better planning of services to meet the requirements of the legal changes.

Our study aimed to determine the prevalence of mental health street triage services in England and to characterise their operational models. We asked whether services were predominantly mobile- or control room-based, how they were staffed, which vehicles and locations were used, the hours of operation and the reasons cited for use.

Our second aim was to systematically collect the views and experiences of police officers who have used services. We identified how regularly officers had contact with individuals experiencing mental health crises, whether they frequently used Section 136 and their confidence levels when dealing with mental health crises. We also asked whether police officers were aware of local street triage services, their preferences regarding their model and whether they found them beneficial. 


\section{Method}

\section{Survey design and samples}

We conducted two surveys. Data were collected between June and October of 2017, using an online survey tool (www.surveymonkey.com). The first was a cross-sectional survey of all 55 National Health Service (NHS) mental health trusts in England.

The second was a survey of operational police officers in the Thames Valley police force. Thames Valley Police provide police services for 2.1 million people residing in Berkshire, Buckinghamshire and Oxfordshire. Street triage services have been available in the region since 2013 because of collaboration between Thames Valley Police and Oxford Health NHS Foundation Trust. The street triage service provides telephone support and a co-response mobile unit (where a police officer and mental health worker respond to incidents in a police vehicle) between the hours of $18.00 \mathrm{~h}$ and $04.00 \mathrm{~h}$.

Both surveys met Health Research Authority criteria for a service evaluation and were approved by Oxford Health NHS Foundation Trust.

\section{Procedure}

For the NHS trust survey, letters were sent to every trust's Chief Executive. Non-responders were followed up twice when necessary, at 4 and 8 weeks. For the police survey, surveys were emailed to all response police constables and police sergeants employed by Thames Valley Police in September 2017, with responses collected until October 2017. A single reminder was sent out to all officers 2 weeks after the initial request.

\section{Survey questionnaire}

The surveys were constructed to address the primary and secondary aims of the project. The surveys took up to $30 \mathrm{~min}$ for participants to complete, and were conducted solely online. We collected demographic information and length of service for all respondents. The survey questionnaires are available from the corresponding authors upon request.

\section{Results \\ Identifying and characterising NHS street triage services}

Prevalence of street triage services

A total of 40 out of 55 (73\%) mental health trusts in England responded to our survey. Of the 40 respondents, 28 (70\%) offered street triage services. Of those that had services, the mean length of provision was 2.9 years, with wide variability from 6 months to 5 years of operation. Most areas reported that services had been available for 2-4 years.

Of those that did not provide a service, two (17\%) had definite plans for introduction. Seven trusts reported having more than one street triage service, crossing different jurisdictions (police and/or social services) in their geographical area, giving a total of 41 street triage services represented in the survey.

\section{Models of street triage}

Eight out of $41(20 \%)$ of the services described a telephone support only street triage service, 19 (46\%) reported a mobile unit and $12(29 \%)$ reported they had both means of response (Fig. 1). Two respondents (5\%) did not specify.

\section{Staffing}

A total of 28 out of 36 respondents (78\%) reported their service was staffed by police officers and mental health staff, and eight out of $36(22 \%)$ reported it was staffed by mental health staff only (a model in which mental health staff provide telephone support or attend police incidents after a referral from the police at the incident).

Services were overwhelmingly led by health staff (27 out of $41 ; 82.5 \%$ ), although several services had police officers as lead (five out of $41 ; 12.5 \%$ ) or a combined leadership model (six out of $41 ; 12.5 \%$ ). One of the services (5\%) did not have a



Fig. 1 Reported frequencies of models of triage. 


\begin{tabular}{|lc|}
\hline \multicolumn{2}{|l|}{ Table 1 Reasons cited for use of street triage } \\
\hline Reasons cited & Percent of respondents \\
\hline Deliberate self-harm & $98 \%$ \\
\hline Previous mental health history & $80 \%$ \\
\hline Substance misuse & $20 \%$ \\
\hline Psychosis & $50 \%$ \\
\hline No alternative support available & $10 \%$ \\
\hline Support Section 136 decision-making & $8 \%$ \\
\hline
\end{tabular}

a. Percentages do not add up to $100 \%$ because of multiple responses per question.

designated lead. Two respondents (5\%) did not specify. On average, there were 2.05 whole-time equivalent staff on duty per shift.

\section{Vehicle and location}

Of the 31 reported mobile services, ten (32\%) used marked and $11(36 \%)$ used unmarked police vehicles. Four (13\%) used personal vehicles or ambulances and six (19\%) respondents reported that they used a combination.

A total of 38 services reported on their main location for street triage services, with $28(74 \%)$ services located at police stations and ten (26\%) located at mental health sites.

\section{Hours and days of operation}

There was a wide range of reported hours and days of operation. Only three of the 28 trusts (11\%) offered 24/7 availability, with the majority (79\%) typically only providing night shifts (usually between late afternoon or early evening and a few hours past midnight).

\section{Methods of contact}

Street triage teams were contacted in a variety of ways, including 999 emergency operators (10\%) and from the police control room (18\%). The most common method, however, was a combination of means (72\%), including 999 calls, control room, individual police officers and other emergency services.

\section{Reasons cited for service use}

Service providers gave a number of reasons for street triage call-outs: 98\% (39 out of 41) reported that call-outs had been made for cases of self-harm and there were also high figures for other reasons, as shown in Table 1.

\section{The views and experiences of police officers regarding street triage services}

\section{Demographic information}

The police survey was sent out to 579 officers, of whom 264 responded, for a response rate of $45.6 \%$. Table 2 presents service and demographic results of respondents.

\section{Mental health training}

A total of 207 out of 256 (81\%) of respondents reported they had received formal mental health training in the past 3 years, often in more than one form. Eight respondents did not respond. This training was generally mandated (181 out of 221 respondents; $82 \%$ ).

\begin{tabular}{lcc}
\hline Table 2 & $\begin{array}{l}\text { Demographic and service characteristics of police } \\
\text { survey respondents }(n=264)\end{array}$ & $\%$ \\
\hline Characteristic & $n$ & \\
\hline Gender & 161 & 61 \\
\hline Male & 94 & 36 \\
\hline Female & 0 & 0 \\
\hline Other & 7 & 3 \\
\hline Prefer not to say & 2 & 0.8 \\
\hline Did not specify gender & & \\
\hline Rank & 74 & 6 \\
\hline Police Constable & 47 & 18 \\
\hline Sergeant & 15 & 0.8 \\
\hline Inspector & 2 & 74 \\
\hline Police Community Support Officer & 5 & 2 \\
\hline Other & 1 & 0.4 \\
\hline Did not answer question & & \\
\hline Department & 131 & 5 \\
\hline Response team & 120 & 50 \\
\hline Investigation team & 12 & 46 \\
\hline Neighbourhood policing teams & 1 & 0.4 \\
\hline Did not specify department & 101 & 38 \\
\hline Length of service & 69 & 26 \\
\hline Served <5 years & 75 & 29 \\
\hline Served 6-10 years & 18 & 7 \\
\hline Served 11-20 years & 1 & 0.4 \\
\hline Served $>20$ years & & \\
\hline Did not specify length of service & & \\
\hline
\end{tabular}

Contact with mental health crises

A total of $87 \%$ (222 out of 255) of respondents reported regular (approximately every shift) face-to-face contact with the public, with $79 \%$ (202 out of 255) reporting weekly or more frequent contact with people in mental health crises; within this subset, $115(45 \%)$ reported daily or more frequent contact (Fig. 2). Respondents reported that on average, four out of their past ten incidents involved mental health crises.

Officers' confidence regarding mental health incidence varied: $71 \%$ (178 out of 252) reported they were at least fairly confident, whereas $10 \%$ (25 out of 252) described themselves as unconfident.

\section{Awareness and use of street triage}

Levels of awareness of the service were high at 97\% (249 out of 256): $92 \%$ of respondents who answered this question had used street triage (234 out of 257) and $92 \%$ of these respondents described the triage service as helpful. Sixty per cent (145 out of 245) had used both mobile units and telephone support.

Respondents were further asked for their experiences of and preferences for the two systems. There was a clear preference for response in person, with $47 \%$ (68 out of 145) reporting this as being more helpful and only one 


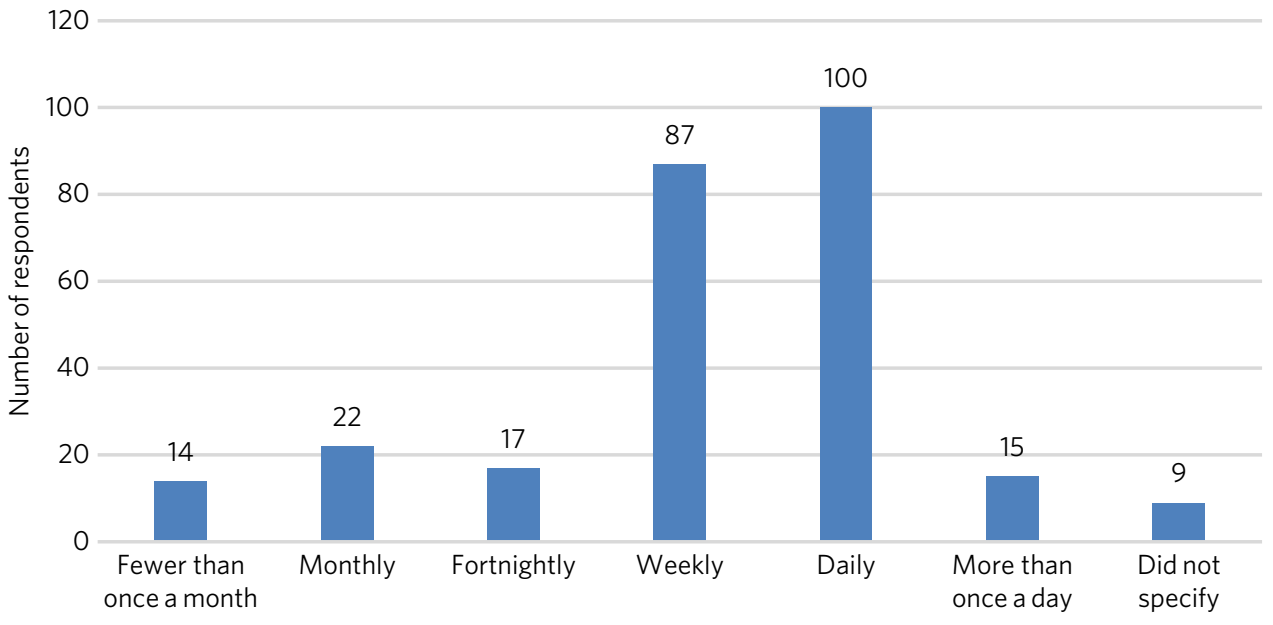

Fig. 2 Frequency of contact with members of the public with mental health problems.

respondent feeding back that telephone support was better. The remainder (52\%; 76 out of 145) reported that both were equally helpful. A total of $98 \%$ of respondents (240 out of 245) overall felt that the service has been beneficial in the Thames Valley area and $71 \%$ (173 out of 245 respondents) felt that it should be available 24 hours a day.

\section{Use of Section 136 and interactions with street triage}

More than half of respondents had used Section 136 of the Mental Health Act 2007 (58\%; 146 out of 251) and only $52 \%$ of those using the powers (76 out of 146) had involved the street triage service in the process. The most common reason cited was the unavailability of the street triage service because of hours of operation or other demands on it (83\%; 58 out of 70).

\section{Officers' free-text responses and feedback}

Sixty respondents made comments in the free-text section, with 58 (98\%) commenting that the service was highly beneficial. Officers noted that the service was 'long overdue' and 'one of the best decisions made by Thames Valley Police and NHS in recent years'. One officer directly commented on its necessity: '[Mental health] is a specialist area and police officers are not mental health specialists'. Additional reported benefits included saving police time and reducing stigma.

Many stated that they wished that the service was available $24 / 7$ or at least extended hours. One officer wrote 'the only downside is that it is not already a 24-h service'. Additional comments referenced the lack of availability of child mental health workers and social workers, as '[police officers] seem to come across a lot of younger people with mental health issues too'.

\section{Discussion}

These surveys are the first attempt to characterise street triage services nationally since the launch of the pilot projects in 2013, and to get a detailed snapshot of police attitudes toward them. It is clear that street triage services, although still a relatively new model of care, are now widespread across England. They have continued to expand in spread and scope since their introduction, understandably given the increasing contact between police officers and those with mental illness. This is also reflected in the changes to the Policing and Crime Act, which will necessitate better police-mental health interagency collaboration; ${ }^{6}$ street triage is best prepared to fill this gap in service.

Our National NHS survey highlights significant variations in street triage models. Hours of operation vary, although usually with an emphasis on evenings, night-times and weekends, with little or no cover during the daytime. Levels of investment vary substantially and are reflected in staffing numbers and types of model; a mobile in-person response is inevitably initially costlier than telephone support. However, the former service is more valued by officers and may be more effective at freeing up police time and allowing for appropriate interventions, and as a result may be more cost-effective. We simply do not know. Future research must concentrate on what the effective elements of street triage are that improve patient experience, reduce 'wasted' police time and improve outcome in terms of health use, functioning and criminal justice interactions.

Most services are located on police premises, but are led by NHS staff. This may be appropriate in the short-term, but there needs to be consideration of whether a merger of personnel would be more effective. There is similar lack of clarity in many funding models, with the key question being 'who should pay for these services?'. We did not specifically explore this in our study, but opinions seem to differ between the three main agencies concerned (the police, health and social care). A hybrid funding model involving the interested parties would likely be most appropriate but this requires negotiation and thought; in these austere times this will not be easy. Future work to determine how to best navigate such financial and institutional barriers to interagency cooperation between the police and health sector is needed.

Police officers from our survey are overwhelmingly supportive of street triage. There was a clear preference for services to exist and to be provided in-person. There was strong support for $24 / 7$ services. There was a high frequency of 
responding to mental health incidents described by participants, supporting the view that mental health work is now 'core police business'. services, heightened by recent changes to legislation that require officers to seek qualified mental health advice before using Section 136, rather than seeking guidance retrospectively. ${ }^{6}$ As mental health crises occur at any time of the day, it was not surprising that the majority of officers in our survey believed that street triage should be available 24/7. Longer hours of operation, more integration and a higher profile may help to improve the training and confidence of officers. ${ }^{8}$ We do not know whether face-to-face triage is more effective than telephone triage. Only one previous study has compared these models. ${ }^{9}$ Their analysis suggested that a face-to-face model can reduce the overall use of Section 136 and increase the proportion resulting in hospital admission, while the telephone-only service did not.

\section{Limitations}

Both surveys may include some selection bias, in common with any survey of this type. However, the respondents in our police survey were fairly large in number, there was a reasonable response rate and they appear representative. Our national NHS survey achieved an excellent response rate of $73 \%$, unusually high for such a survey and likely to be protective against selection bias.

\section{Implications}

In conclusion, street triage services are widespread across England and increasingly seen as a permanent part of our response to mental health crises. Despite this, models vary significantly and there is little or no evidence on which to base good practice or commissioning decisions. Outcome data is almost non-existent. Our surveys show a clear appetite for services to exist and to be strengthened. Recent changes to the Police and Crime Act will almost certainly stimulate this, with officers being required to seek advice in real time. Public concerns regarding civil liberties and the unacceptable cases of people being stranded in police cells while arrangements are made also make the case that mental health expertise during these crises is vital.

However, the increase in use of street triage will require greater resources and further investment. Questions should be asked as to how services can be organised most effectively and efficiently and how they can most benefit those experiencing mental health crises. Evidence is urgently needed regarding the effects of street triage services and, crucially, what elements of the service are effective in reducing risk and improving outcome. Future studies could also investigate mental health staff or patients' perceptions regarding the quality of triage care.

\section{Funding}

This research was funded by the National Institute for Health Research (NIHR) Collaboration for Leadership in Applied Health Research and Care Oxford at Oxford Health NHS Foundation Trust (grant number BZR00180). The views expressed are those of the author(s) and not necessarily those of the NHS, the NIHR or the Department of Health

\section{About the authors}

Abirami Kirubarajan is a Medical Student at the University of Toronto Faculty of Medicine, Canada. Stephen Puntis is a National Institute for Health Research Post-Doctoral Fellow at University of Oxford, Warneford Hospital, UK. Devon Perfect is an Assistant Psychologist at Oxford Health NHS Foundation Trust, Warneford Hospital, UK. Marc Tarbit is Chief Inspector of Thames Valley Police at St Aldates Police Station, UK. Mary Buckman is Head of Social Care for Oxford Health NHS Foundation Trust, Warneford Hospital, UK. Andrew Molodynski is a Consultant Psychiatrist with Oxford Health NHS Foundation Trust, Warneford Hospital, UK.

\section{References}

1 Coleman TG, Cotton DH. Reducing risk and improving outcomes of police interactions with people with mental illness. J Police Crisis Negot 2010; 10(1-2): 39-57

2 Department of Health. Mental Health Act. The Stationary Office, 2007 (https://www.legislation.gov.uk/ukpga/1983/20/section/136).

3 Riley G, Freeman E, Laidlaw J, Pugh D. 'A frightening experience': detainees' and carers' experiences of being detained under Section 136 of the Mental Health Act. Med Sci Law 2011; 51(3): 164-9.

4 Wells W, Schafer JA. Officer perceptions of police responses to persons with a mental illness. Policing 2006; 29(4): 578-601.

5 Care Quality Commission. Monitoring the Mental Health Act in 2013/ 14. Care Quality Commission, 2015 (https://www.cqc.org.uk/sites/ default/files/20150204_monitoring_the_mha_2013-14_report_web.pdf).

6 Home Office. Policing and Crime Act 2017. The Stationary Office, 2017 (http://www.legislation.gov.uk/ukpga/2017/3/part/4/chapter/4/enacted).

7 Adebowale L. Independent Commission on Mental Health and Policing Report. Independent Commission on Mental Health and Policing, 2013 (http://www.turning-point.co.uk/media/621030/independent_commission_on_mental_health_and_policing_main_report.pdf).

8 Reveruzzi B, Pilling S. Street Triage. Report on the Evaluation of Nine Pilot Schemes in England. University College London, 2016 (https://s16878. pcdn.co/wp-content/uploads/2016/09/Street-Triage-Evaluation-FinalReport.pdf).

9 Jenkins O, Dye S, Obeng-Asare F, Nguyen N, Wright N. Police liaison and section 136: comparison of two different approaches. BJPsych Bull 2017; 41(2): 76-82. 